\title{
Penile Fracture with Partial Urethral Tear: A Case Report with The Review of Literature
}

\author{
Mohamed S. Al-Masruri' ${ }^{1}$, Jusephkunju Mathew ${ }^{2}$ \\ Urology Division, Department of Surgery, Sultan Qaboos University, Sultanate of Oman. ${ }^{1}$ \\ Urology Division, Department of Surgery, Sultan Qaboos University, Sultanate of Oman. ${ }^{2}$ \\ *Corresponding Author: Dr. Mohamed S.Al-Masruri,MD, Urology GFP Resident, Urology Division, \\ Department of Surgery, College of Medicine \& Health Sciences Sultan Qaboos University, P.O. Box 35, Al- \\ Khoud 123, Sultanate of Oman
}

\begin{abstract}
Objectives: To emphasize the need of high suspicion to rule out associated urethral tear in patients with penile fracture.

Introduction: Penile fracture is a traumatic rupture of the tunica albuginea of one or both corpora cavernosa due to sudden bending of penile shaft during rigid erection.

Case report: A 43-year-old man presented to the emergency department with a history of trauma during sexual intercourse with sudden loss of erection, deformity and bleeding per urethra. Retrograde urethrogram showed extravasation of contrast from the proximal penile urethra. Emergency exploration showed a large tear involving both cavernosa near the base of penis with a partial urethral tear. Primary repair was done. On Discharge, patient was advised to keep Foleys catheter for 10days and to avoid sexual intercourse for about 4weeks.

Conclusion: Penile fracture is a surgical emergency which needs immediate surgical repair to preserve the erection, voiding and to avoid long term sequelae.
\end{abstract}

Keywords: penile fracture, hematoma, corpora cavernosa, urethral injury, erectile dysfunction.

\section{Cover Letter:}

To Whom it may Concern.

Please consider our case report of (Penile fracture with partial urethral tear: A case report with the review of literature) for publication in ARC urology journal. We certify that this paper has not been submitted for publication elsewhere and will not be submitted as to another publication. Likewise, this paper has not been published elsewhere either in part or in its entirety in either print or electronic format. Upon acceptance of this manuscript, the copyright will transfer to ARC Urology Journal.

\section{Funding:}

The author(s) received no financial support for the research, authorship, and/or publication of this article.

\section{INTRODUCTION:}

Penile fracture is an uncommon urological emergency from blunt injury to the erect penis with a reported incidence of 1 in 75,000 (1). It happens due to a tear in tunica albuginea and corpora cavernosa as a result of forceful bending of erect penile shaft. During erection tunica albuginea gets thinned out to $0.5 \mathrm{~mm}$ from $2-3 \mathrm{~mm}$ in the flaccid state making penis highly vulnerable to injury from any further sudden increase in the intra-cavernous pressure (2). True incidence and mechanisms of injury is likely underreported due to the stigma attached. Common situations where penile fracture can happen are intercourse and masturbation, accounting for $48 \%$ and $39 \%$ of cases in one series (4). Most cases of penile fracture occur without urethral injury. Reported incidence of associated urethral injury is $0-38 \%$ (5). In this study, we present a case of penile fracture with urethral tear.

\section{Anatomy of penile fracture:}


A penile fracture happens due to a tear in the tough tunica albuginea which covers both corpora cavernosa. Deep fascia known as Buck's fascia encloses both corpora cavernosa and the corpus spongiosum. The membranous layer of the superficial fascia known as Colles' fascia is continuous with Scarpa's fascia (figure1). Extent of hematoma depends on the coverings torn and time. If the bucks' fascia is intact, the hematoma will be localized to the penis with a sleeve like configuration along the penile shaft (3). Whereas, if buck's fascia is ruptured, the hematoma is limited by the attachments of the overlying Colles' fascia to the perineal body and fascia lata in the upper thigh leading to the butterfly bruising in the perineum and has the potential to extent up the upper abdomen and chest to the clavicles. (figure 2) (3). Hematoma is usually limited to the penis, scrotum and suprapubic region as in our case.

\section{Case report}

A 43-year-old gentleman, presented to our emergency department in 2021, after 8 hours of having a blunt injury to the penis during sexual intercourse in the classical position. During intercourse, his penis slipped out of the vagina and hit hard against the bony pelvis of the partner. He heard a cracking sound followed by immediate loss of erection. Later he noticed swelling with purple discoloration and deformity of his penis. Initially he tried to ignore the symptoms as he was ashamed to seek help but later decided to come to the hospital on noticing bleeding per urethra. An informed consent was taken from the patient to be used for research purpose without mentioning his personal details.

On Examination he was found to have extensive penile hematoma extending to the suprapubic area with eggplant deformity with fresh blood at the meatus. On palpation, no defect could be felt in the corpora. Scrotum was normal, and bladder was not distended (figure 3).

Patient was shifted to the radiology suite for a retrograde urethrogram to assess urethral injury. (figure 4).

Patient was admitted in the ward and posted for emergency penile and urethral repair. Consent was obtained after informing the possible complications like urethral stricture, fistula, penile deformity, erectile dysfunction and the increased incidence of long-term sequelae without repair. Under spinal anesthesia, 3. CONCLUSION: degloving of the penis was done down to the peno-scrotal junction using a circumcoronal incision after inserting a Foley catheter with care. A $4 \mathrm{~cm}$ transverse tear was identified in the lateral and ventral aspect of the left corpora near the base of penis, extending into the ventral aspect of right corpora and involving half of penile urethra exposing the Foley catheter (figure 5). Both the tunica albuginea and the overlying buck's fascia were lacerated with dark clots plugging the cavernosal tissue.

Hematoma was evacuated and the torn edges of the tunica albuginia and urethra were identified. Foleys catheter was removed to ensure identification of the full extent of the urethral injury, which was $50 \%$ of the circumference. Tunica albugina of both corpora cavernosa were repaired using 4-0 prolene as running suture and urethra was closed using 4-0 PDS as interrupted sutures (figure 6). A 16 F Foleys catheter was reinserted easily. Bucks fascia was approximated using 3-0 monocryl. Patient had a spontaneous rigid erection on table with no deformity. Penile dressing was done with mild compression. Patient was discharged the next day with an advice to avoid sexual intercourse for 4 weeks. He voided freely with a good stream following Foleys catheter removal on the 10th day. On follow up, it was difficult to get in touch with the patient, he was contacted and claimed having good urine stream with no erectile dysfunction.

\section{DISCUSSION}

Early surgical intervention is found to be the best in term of short hospital stay, low morbidities and early regaining of normal sexual activity (7).Conservative management alone can cause complications ranging between 10-53\% including penile curvature, pain during erection, arteriovenous fistula and erectile dysfunction (7). Often clinical examination is enough to diagnose penile rupture but MRI and ultrasound are useful investigations. Documenting intact corpora cavernosa on MRI can avoid surgical exploration is rare cases of isolated deep dorsal vein tear. Associated urethral rupture is very rare and reported incidence is $0-38 \%$ (5) (6). Clinical presentation related to urethral rupture includes hematuria, voiding difficulty and bleeding per urethra or blood at the meatus. Suspected urethral injury should be investigated with at least a urethrogram as it may be missed on surgical exploration.

Penile fracture is a relatively rare urological emergency which requires early surgical 
intervention. Surgical exploration and repair are required to preserve the penile erection and voiding function. Possibility of associated urethral tear should be investigated, whenever there is a clinical suspicion.

\section{REFERENCES:}

[1]. Koifman L, Barros R, Júnior RA, Cavalcanti AG, Favorito LA: Penile fracture: diagnosis, treatment and outcomes of 150 patients. Urology 2010;76:14881492.

[2]. Brock G, Hsu GL, Nunes L, von Heyden B, Lue TF. The anatomy of the tunica albuginea in the normal penis and Peyronie's disease.J Urol 1997; 157(1): $76 \square 81$.

[3]. Reynd, J., Brewster, s., Biers, s. and Neal, N., n.d. Oxford Handbook of Urology. 4th ed. pp.542-543.

[4]. Amer, T., Wilson, R., Chlosta, P., AlBuheissi, S., Qazi, H., Fraser, M. and Aboumarzouk, O., 2021. Penile Fracture: A Meta-Analysis.

[5]. Yapanoglu T, Aksoy Y, Adanur S, Kabadayi $B$, Ozturk G, Ozbey I.Seventeen years' experience of penile fracture: conservative vs.surgical treatment. J Sex Med 2009; 6(7): $2058 \square 63$.

[6]. Eke N. Fracture of the penis. Br J Surg 2002; 89(5): 555 $\square 65$.

[7]. Yamaçake, K., Tavares, A., Padovani, G., Guglielmetti, G., Cury, J. and Srougi, M., 2013. Long-term Treatment Outcomes Between Surgical Correction and Conservative Management for Penile Fracture: Retrospective Analysis. Korean Journal of Urology, 54(7), p.472.

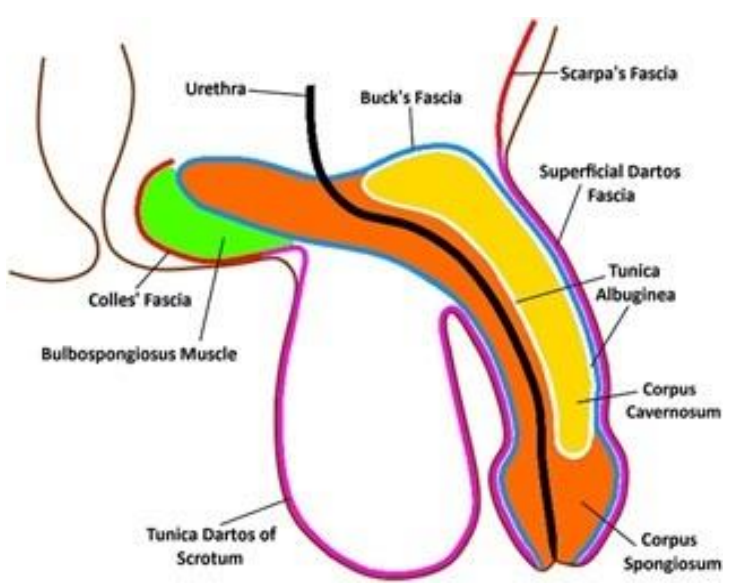

(Figure 1) Napier, D., 2018. The role of ultrasound in the diagnosis of penile fracture. Sonography, 6(1), pp.15-23.
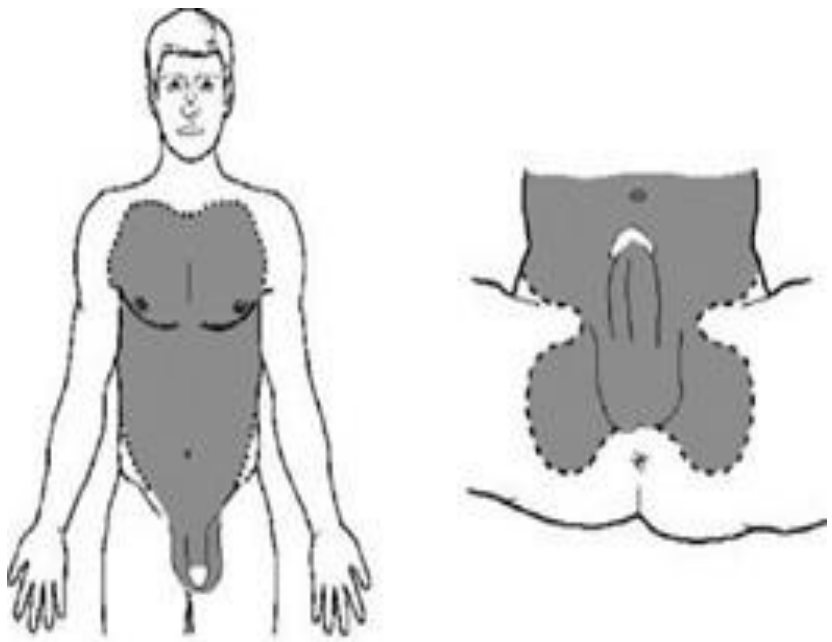

(figure 2) butterfly bruise following Bucks fascia rupture (from Oxford of urology figure11.11) page542)

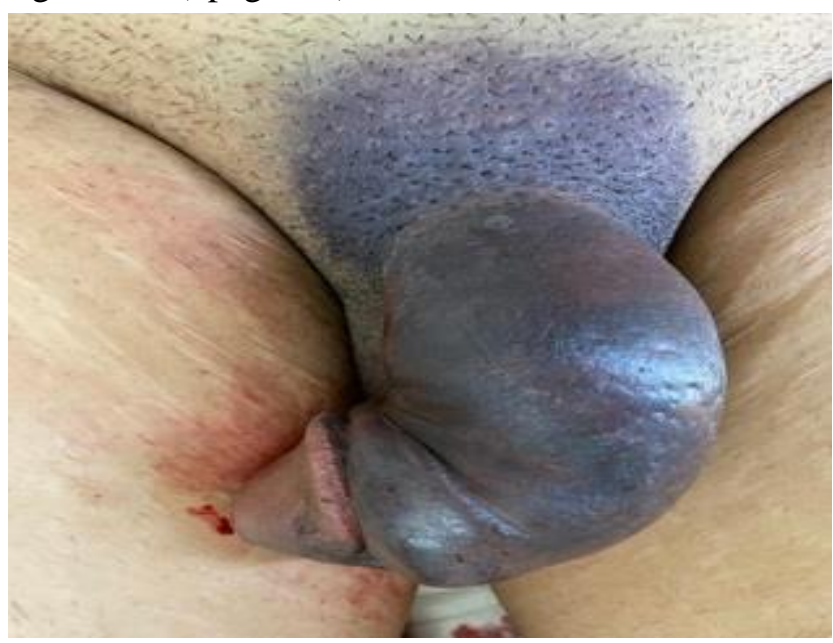

(Figure 3): Penile hematoma is seen extending to the suprapubic region with the classical eggplant deformity and meatus bleeding.

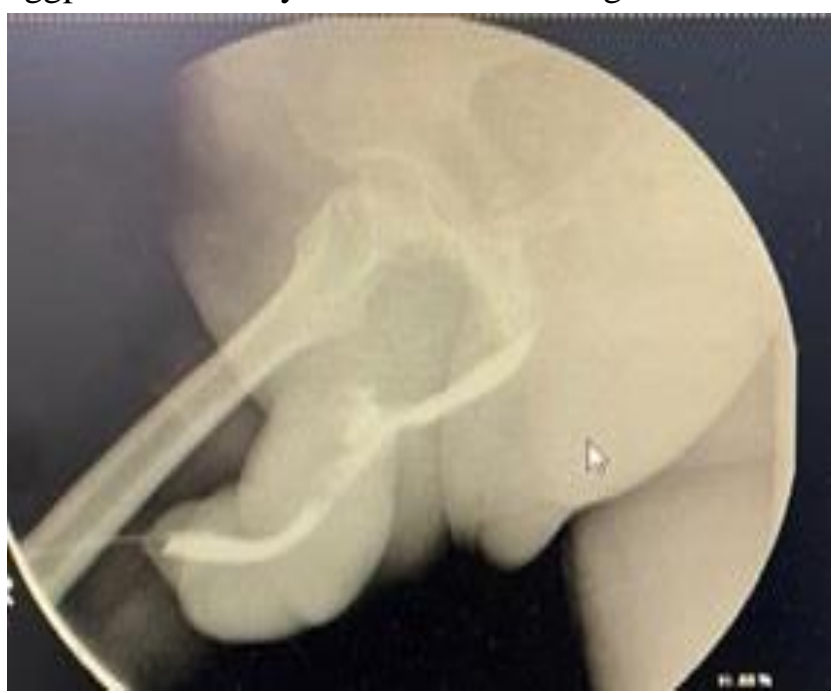

(Figure 4): urethrogram showing contrast extravasation from the proximal urethra with contrast filling the bulbar urethra suggesting a partial tear. 
Penile Fracture with Partial Urethral Tear: A Case Report with The Review of Literature

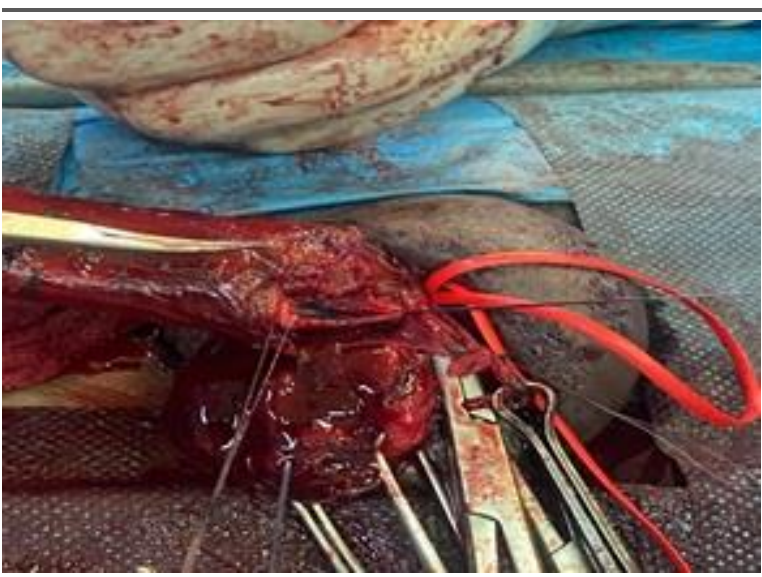

(Figure 5): urethral injury exposing the Foley catheter in the lumen.

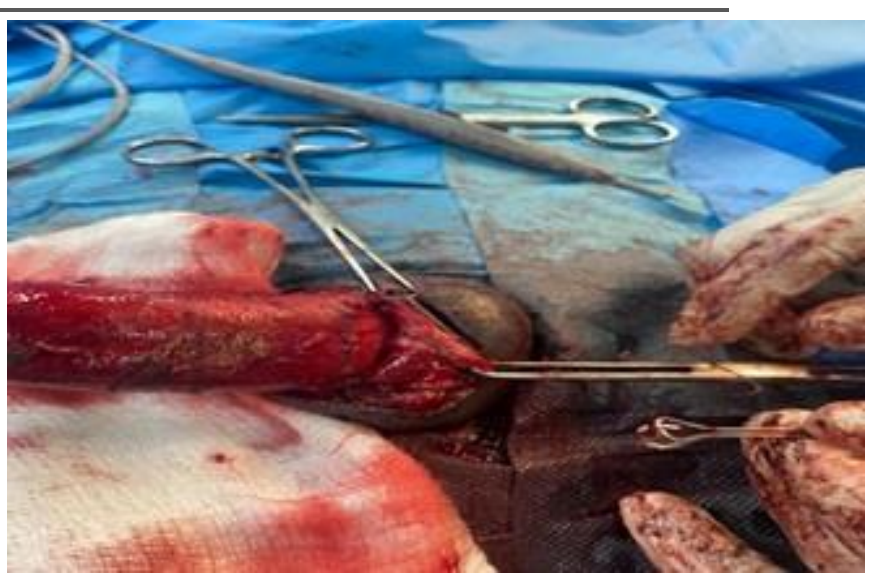

(Figure 6): Buck's fascia closed over corpora cavernosum and urethral repair.

Citation: Mohamed S. Al-Masruri, Jusephkunju Mathew, Penile Fracture with Partial Urethral Tear: A Case Report with The Review of Literature. ARC Journal of Urology. 2020; 6(1):21-24. DOI: https://doi.org/ 10.20431/2456-060X.060104.

Copyright: (c) 2021 Authors. This is an open-access article distributed under the terms of the Creative Commons Attribution License, which permits unrestricted use, distribution, and reproduction in any medium, provided the original author and source are credited. 